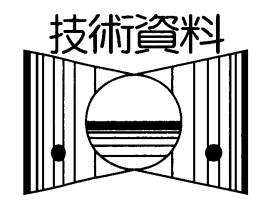

\title{
舶用ディーゼル潤滑油污れの計測・評価に関する考察 一ペンタン不溶解分と污染粒子—*
}

\author{
木 村 功** 東 忠 則 $* * *$ 住 本 守 央 $* * * *$
}

Consideration on Measurement Methods and Estimation of Lub. oil Contamination for Marine Diesel Engines.

By Isao Kimura, Tadanori Azuma and Morio Sumimoto

In the conventional system of lubrication, lubricating oil is renewed with fresh oil after it is used for some period. Accordingly,waste oil is generated in the conventional system. The authors have developed a new system that makes it possible to use lubricating oil semi-permanently without oil renewal. In the new system, therefore, no waste oil is generated and it is enough to supply only a small amount of fresh oil sometimes to compensate for the lost oil. This system has been working well in about one thousand units of marine and cogeneration diesel engines in practice. The new system always keeps the lubricating oil clean as the kidney of animals kepps their blood always clean. This is why lubricating oil can be used semi-permanently and the new system is called kidney system. In our experience of the kidney system in practical use, we have come to know that there are some problems in the present methods of measurement and estimation of contamination of lubricating oil in marine diesel engines This paper reports about our study on measuring normal pentane insolubles and particles in used lubricating oil.

Key words; Measurement and estimation of LO, normal pentane insolubles, cantaminant particles.

\section{1. まえがき}

筆者等はLO系で発生する污れを速やかに除去 し，LOと添加剤の消耗分を補給することによって LO性状を略一定に維持し, LOを半永久的に使用 してLOの消費量を低減し，廃油をゼロにするシス テム（Kidney system）を開発し，既に，1000台以 上の舶用ディーゼルやコージェネデイーゼル，約 60 社の工場洗浄油, 約50社の油圧機器メーカーで実 用化されている ${ }^{(1)}{ }^{(2)}$. 油圧機器への応用ではST

*原稿受付 平成 12 年 3 月 29 日

第63回学術講演会（平成11年10月13日）

**正会員 株式会社住本科学研究所（神戸市兵庫区本町 1-6-15)

$* * *$ 正会員 帝京大学 (宇都宮市豊郷台 $1-1$ )

$* * * *$ 正会員 株式会社住本科学研究所（横浜市港南区港南台 $1-4-13)$
社のパワーショベルで, 作動油は使用時間が長い ほどきれいになり，新油よりもきれいになった。 従来は出荷後 1 年間で, 出荷台数の約 1 割にメ一 カーが補償すべきトラブルが発生していたが, kidney systemによってトラブルは，ほぼ完全に消滅 した ${ }^{(3)}$. 肥料工場の圧縮機で生ずる含油廃水か ら, 新油よりもきれいなLOを再生している例もあ る ${ }^{(4)}$.

筆者等はkidney systemによるLO管理の実務の 経験から, 従来のLO污染度の計測・評価法の中 に，必要かどうかを含めて検討を要するものがあ ると考えている，本報では実機データを基にして， ペンタン不溶分の遠心分離法と, 粒子数測定法に ついて考察する. 


\section{2. ペンタン不溶分と粒子測定法に関する 問題点と考察}

\subsection{ASTM, A 法とB法の問題点}

A法はノルマルペンタン（n-Pentane）投入後, 通常，600〜 700Gの遠心分離機で不溶分を分離す る。この方法の問題点を列挙するとつぎの通りで ある。（1）A法では凝集戍を使用しない計測法で あるから, 清浄分散剤によって不溶分は微粒子の 形状で分散されているため, 大部分は遠心分離で きない。（2）実際に遠心分離される量は，清浄分 散剤の濃度や特性に左右されるであろう。この方 法では，600〜 700Gで分離可能な大粒子のみが計 測され，真の不溶分の量は分からない。（3）更油 に2サイクル・クロスヘッドエンジンで, ペンタン 不溶解分 $1.5 \%$ ，4サイクル・トランクピストンエ ンジンで $2.5 \%$ 基準が示されているが，(5) 計測 值が真の值を示していないのであるから，この基 準值は根拠が薄くなる。したがって, エンジン保 守の立場から，この方法は好ましくないと考える。

B法は凝集剤によって不溶分を凝集させたあと

\section{表1 |社 エンジン潤滑油不溶解度分測定結果}

\begin{tabular}{|c|c|c|c|c|c|}
\hline \multirow[b]{2}{*}{ No } & \multirow{2}{*}{$\begin{array}{c}\text { 清浄時間 } \\
\mathrm{Hr} \\
\end{array}$} & \multicolumn{2}{|c|}{ 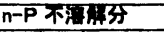 } & \multirow{2}{*}{ 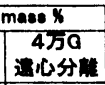 } & \multirow{2}{*}{$\begin{array}{l}\text { メンブン } \\
\text { フィルタ- } \\
5 \mu \mathrm{m}\end{array}$} \\
\hline & & $\begin{array}{l}\text { ASTM } \\
\text { A 法 }\end{array}$ & $\begin{array}{l}\text { ASTM } \\
\text { B法 }\end{array}$ & & \\
\hline 1 & 125 & $<0.01$ & $<0.01$ & & \\
\hline 2 & 400 & $<.001$ & $<0.01$ & & \\
\hline 3 & 1,140 & $<0.01$ & $<0.01$ & $\begin{array}{l}0.04 \\
\text { 約35 } \mathrm{mg} \\
/ 100 \mathrm{ml} \\
\end{array}$ & $\begin{array}{c}1.8 \mathrm{mg} \\
/ 100 \mathrm{ml}\end{array}$ \\
\hline 4 & 2,000 & $<0.01$ & $<0.01$ & & \\
\hline
\end{tabular}

表2 I社 エンジン潤滑油粒子数測定

\begin{tabular}{|c|c|c|c|c|c|c|c|c|}
\hline \multirow[b]{2}{*}{ NO } & \multirow{2}{*}{$\begin{array}{c}\text { 清浄時間 } \\
\mathrm{Hr}\end{array}$} & \multicolumn{6}{|c|}{ 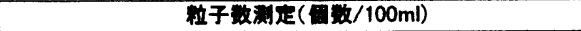 } & \multirow{2}{*}{$\begin{array}{l}\text { ISO } \\
4406\end{array}$} \\
\hline & & $5 \sim 15 \mu \mathrm{m}$ & $15 \sim 25$ & $25 \sim 50$ & $50 \sim 100$ & $>100$ & NAS & \\
\hline 1 & 125 & $\begin{array}{c}804,817 \\
(12)\end{array}$ & $\begin{array}{c}39,617 \\
(10)\end{array}$ & $\begin{array}{r}9,267 \\
(11)\end{array}$ & $\begin{array}{r}1,100 \\
(10)\end{array}$ & $\begin{array}{l}50 \\
(8)\end{array}$ & 12 & $20 / 16$ \\
\hline 2 & 400 & $\begin{array}{c}282,217 \\
(11)\end{array}$ & $\begin{array}{c}11,867 \\
(9)\end{array}$ & $\begin{array}{c}2,200 \\
(9)\end{array}$ & $\begin{array}{r}317 \\
(8)\end{array}$ & $\begin{array}{l}33 \\
(8)\end{array}$ & 11 & 19/14 \\
\hline 3 & 1,140 & $\begin{array}{c}141,033 \\
(10)\end{array}$ & $\begin{array}{c}15,067 \\
(9)\end{array}$ & $\begin{array}{c}2,433 \\
(9)\end{array}$ & $\begin{array}{r}267 \\
(8)\end{array}$ & $\begin{array}{c}0 \\
(0)\end{array}$ & 10 & $18 / 15$ \\
\hline 4 & 2,000 & $\begin{array}{c}178,967 \\
(10)\end{array}$ & $\begin{array}{c}16,500 \\
(9)\end{array}$ & $\begin{array}{c}2,133 \\
(9)\end{array}$ & $\begin{array}{r}200 \\
(8)\end{array}$ & $\begin{array}{c}0 \\
(0)\end{array}$ & 10 & $18 / 15$ \\
\hline
\end{tabular}

遠心分離するので，污れの絶対量を評価するには， 一見, A法よりも秀れているように思われる。し かし, このB法ではA法と同じ 600〜 700Gの分離 力が問題である.

\section{2 実機データによる考察}

\section{2 .1 污染物の主要存在領域}

表 1 は, I社 4 サイクル機関のシステムオイル 2900Lをkidney systemで清浄し，表に示す時間毎 に分析した結果である。不溶分はA法，B法ともに 非常に少なく計測不能であり，1.5\%の更油基準か らすれば，このLOは非常にきれいと判定される.

油圧機器における作動油は, 通常NAS 8級また は，それよりもきれいな油が用いられるが，最近， LO管理にNAS PISO - 4406を用いるところが現 れ，LO中の粒子測定が行われている．表2は，表1 （I社）のLOの粒子測定結果である。例えば粒子直 径 $\mathrm{d}=5 \sim 15 \mu \mathrm{m}$ に着目すると，清浄時間と共に粒 子数は約 80 万個, 30 万個, 14 万個と減少し, 表 1 で示すようにA法，B法ともに不溶分は計測不能の

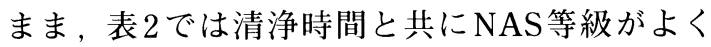
なっている. 清浄時間 $1140 \mathrm{hr}$ (No.3) の時の $\mathrm{d}=$ 5〜 $15 \mu \mathrm{m}$ の粒子は約 14 万個であり，そのために NAS10級であるから，作動油の考え方を適用すれ ば，この清浄度のLOはあまりよくないと判定され る.これに対して表1で，不溶分はASTM，A，B 法ともに計測不能なほどに微量であり，LOとして の清浄度は全く問題ないと判定され，LOの評価は 不溶分で合格，粒子で不合格となる。

眓1は，表2のLO（I社）をマイクロトラック法 によって，清浄 $1140 \mathrm{hr}$ (No.3) の粒度分布を計測 したものである.これによると， $\mathrm{d}>5 \mu \mathrm{m}$ の大き い粒子の数は, $5 \mu \mathrm{m}$ 以下の粒子数に比べて無視で きる程度であり，この状態で供試LO中に残存する 粒子は, $\mathrm{d}<5 \mu \mathrm{m}$ の微粒子が全てと言って も過言ではない，粒度分布から不溶分の容 積を計算すると， $\mathrm{d}>5 \mu \mathrm{m}$ の比較的大きな 粒子の占める容積は, 全粒子が占める容積 の約 $1 \%$ に過ぎない。これは横松等の報告 (6) とも一致する.したがって表2の粒子数 で污染度を評価すると，全体のわずか $1 \%$ で，LOの良否を評価していることになる。 表 1, No.3の $1140 \mathrm{hr}$ の計測で, A法とB 


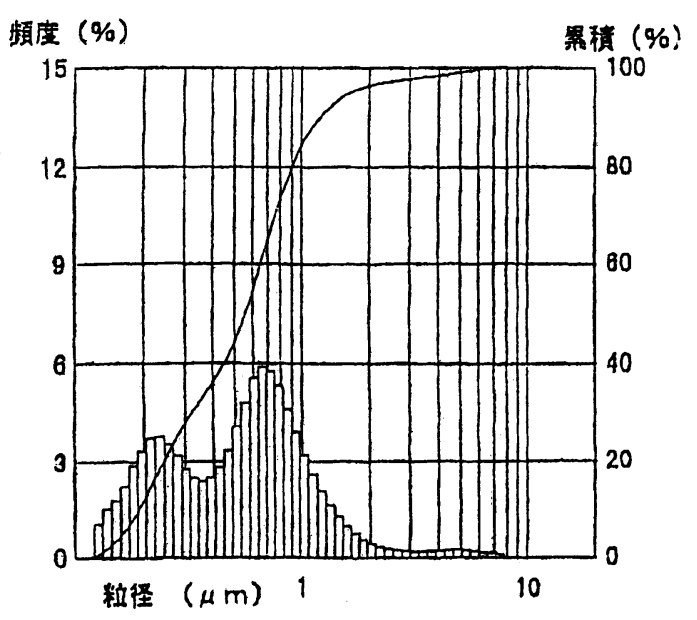

図1 粒度分布測定結果

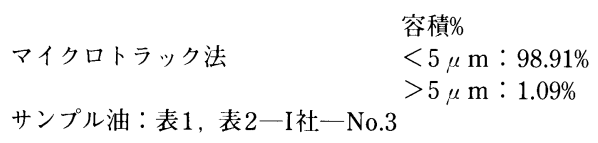

法による不溶分は計測不能なほどの微小量である が，これは遠心分離機の能力が低く小さい粒子を 分離できないからである. $\mathrm{d}<5 \mu \mathrm{m}$ 級の微小粒子 が多いのであるから, 遠心分離機の能力が高けれ ば，不溶分が計測されるはずである。これを確認 するために, No.3 (1140hr) とNo.4 (2000hr) のLO を, $5 \mu \mathrm{m}$ メンブランフィルタと 4 万Gの遠心分離
機で処理した。その結果, 表1に示されるように, $1140 \mathrm{hr}$ で不溶分は，メンブランフィルターによる $5 \mu \mathrm{m}$ 以上の粒子が $1.8 \mathrm{mg}, 4$ 万 $\mathrm{G}$ 遠心分離による 不溶分が約 $35 \mathrm{mg}$ である. $2000 \mathrm{hr}$ では 4 万G遠心分 離で, 不溶分 $0.01 \%(9 \mathrm{mg})$ となった.

表3と表4は，K社と $\mathrm{M}$ 社における 2 サイクルエ ンジン用LOの計測結果である。K社は従来システ ムで清浄されていたLO系統にkidney systemを導 入し，1997.8/8から97. 12/3まで約 3 ヶ月間, kidney systemによって連続清浄時の計測結果であ る. ISO - 4406方式では $22 ／ 17 の$ 污れである. ISO 方式の X $/ \mathrm{Y}$ の分子 $\mathrm{X}$ は, 直径 $5 \mu \mathrm{m}$ 以上の粒 子数の総数のコードNoであり, $\mathrm{Y}$ は $15 \mu \mathrm{m}$ 以上の 粒子数のコードNoである.X, Y ガ大きいほど粒 子数が多い。運転開始から約 4 力月後の, 計測 No.8に着目すると, この時B法による不溶分は計 測不能であるが，4万 $\mathrm{G}$ 計測では，0.03\%（約 $26 \mathrm{mg}$ ）である。それから約 1 力月後の計測では ISO, $22 / 17$ と変わらないが, 4 万 G 計測では不溶 分は計測不能の微量となっている.

表4に示すように，M社は同様に97.7／10から 98. $7 / 31$ の約 1 年間, 連続清浄時に計測した。運 転開始から約 1 年後のNo.5ではISO - 4406で $21 /$ 16 であるが，B法による不溶分は計測不能，4万 $\mathrm{G}$ では $0.15 \%$ (約 $135 \mathrm{mg}$ ) である.

K社のNo.8とM社のNo.6を比較すると， 4 万 G

\section{表3 K社 エンジン潤滑油清浄結果}

\begin{tabular}{|c|c|c|c|c|c|c|c|c|c|c|}
\hline \multirow[b]{2}{*}{$\mathrm{NO}$} & \multicolumn{6}{|c|}{ 粒 子 数 測 定（個数 $/ 100 \mathrm{ml}$ ) } & \multirow{2}{*}{$\begin{array}{c}\text { ISO } \\
4406 \\
\end{array}$} & \multicolumn{2}{|c|}{ n-p不溶解分 (\%) } & \multirow{2}{*}{$\begin{array}{c}\text { 洗浄時間 } \\
\mathrm{hr}\end{array}$} \\
\hline & $5 \sim 15 \mu \mathrm{m}$ & $15 \sim 25$ & $25 \sim 50$ & $50 \sim 100$ & $>100$ & NAS & & $4 万 G$ & B法 & \\
\hline 1 & $\begin{array}{c}1,724,370 \\
(>12)\end{array}$ & $\begin{array}{c}66,217 \\
(11) \\
\end{array}$ & $\begin{array}{c}4,533 \\
(10)\end{array}$ & $\begin{array}{l}180 \\
(7)\end{array}$ & $\begin{array}{l}60 \\
(8)\end{array}$ & $>12$ & $21 / 17$ & & & 始動前 \\
\hline 2 & $\begin{array}{c}1,518,850 \\
(>12)\end{array}$ & $\begin{array}{c}33,927 \\
(10)\end{array}$ & $\begin{array}{c}1,440 \\
(8)\end{array}$ & $\begin{array}{l}80 \\
(6)\end{array}$ & $\begin{array}{l}30 \\
(7)\end{array}$ & $>12$ & $21 / 16$ & & & 190 \\
\hline 3 & $\begin{array}{c}1,032,840 \\
(>12)\end{array}$ & $\begin{array}{c}8,100 \\
(8)\end{array}$ & $\begin{array}{l}627 \\
(7)\end{array}$ & $\begin{array}{l}87 \\
(6)\end{array}$ & $\begin{array}{l}20 \\
(7) \\
\end{array}$ & $>12$ & $21 / 14$ & & & 360 \\
\hline 4 & $\begin{array}{c}547,777 \\
(12) \\
\end{array}$ & $\begin{array}{c}2,533 \\
(6)\end{array}$ & $\begin{array}{c}353 \\
(6)\end{array}$ & $\begin{array}{l}60 \\
(6)\end{array}$ & $\begin{array}{l}17 \\
(7)\end{array}$ & 12 & $20 / 12$ & & & 740 \\
\hline 5 & $\begin{array}{c}309,113 \\
(11)\end{array}$ & $\begin{array}{c}1,503 \\
(6)\end{array}$ & $\begin{array}{l}190 \\
(5)\end{array}$ & $\begin{array}{l}30 \\
(5)\end{array}$ & $\begin{array}{l}10 \\
(6)\end{array}$ & 11 & $19 / 11$ & & & 1,000 \\
\hline 6 & $\begin{array}{c}212,705 \\
(10) \\
\end{array}$ & $\begin{array}{c}2,705 \\
(6)\end{array}$ & $\begin{array}{c}380 \\
(6)\end{array}$ & $\begin{array}{l}35 \\
\text { (5) }\end{array}$ & $\begin{array}{l}10 \\
(6) \\
\end{array}$ & 10 & $18 / 17$ & & & 1,520 \\
\hline 7 & $\begin{array}{c}2,645,770 \\
(>12)\end{array}$ & $\begin{array}{c}117,085 \\
(12)\end{array}$ & $\begin{array}{c}4,325 \\
(10)\end{array}$ & $\begin{array}{l}130 \\
(7) \\
\end{array}$ & $\begin{array}{l}15 \\
(7) \\
\end{array}$ & $>12$ & $22 / 17$ & & & 1,650 \\
\hline 8 & $\begin{array}{c}2,621,870 \\
(>12)\end{array}$ & $\begin{array}{c}124,080 \\
(12) \\
\end{array}$ & $\begin{array}{l}4,970 \\
(10)\end{array}$ & $\begin{array}{l}260 \\
(8)\end{array}$ & $\begin{array}{l}35 \\
(8) \\
\end{array}$ & $>12$ & $22 / 17$ & $\begin{array}{l}* \\
0.03\end{array}$ & $<0.01$ & 2,500 \\
\hline 9 & $\begin{array}{c}2,452,380 \\
(>12)\end{array}$ & $\begin{array}{c}106,195 \\
(12)\end{array}$ & $\begin{array}{c}4,315 \\
(10)\end{array}$ & $\begin{array}{l}195 \\
(8)\end{array}$ & $\begin{array}{l}60 \\
(8)\end{array}$ & $>12$ & $22 / 17$ & $<0.01$ & $<0.01$ & 3,500 \\
\hline 10 & $\begin{array}{c}414,665 \\
(11)\end{array}$ & $\begin{array}{c}8,195 \\
(8)\end{array}$ & $\begin{array}{l}990 \\
(7)\end{array}$ & $\begin{array}{l}150 \\
(7)\end{array}$ & $\begin{array}{l}70 \\
(9) \\
\end{array}$ & 11 & $19 / 14$ & $<0.01$ & $<0.01$ & 3,640 \\
\hline 11 & $\begin{array}{c}68,660 \\
(9) \\
280 \text { 不 }\end{array}$ & $\begin{array}{c}5,935 \\
(8) \\
\end{array}$ & $\begin{array}{c}1,530 \\
(8) \\
\end{array}$ & $\begin{array}{l}530 \\
(9)\end{array}$ & $\begin{array}{l}205 \\
(10) \\
\end{array}$ & 10 & $17 / 14$ & & & 5,450 \\
\hline
\end{tabular}


表4 M社 エンジン潤滑油清浄結果

\begin{tabular}{|c|c|c|c|c|c|c|c|c|c|c|c|}
\hline & & 粒 子 & 数 測 & (個数 $/ 10$ & & & ISO & $n-p$ 不渺 & 雮分 (\%) & 洗浄時間 & サンプル \\
\hline NO & $5 \sim 15 \mu \mathrm{m}$ & $16 \sim 25$ & $25 \sim 50$ & $50 \sim 100$ & $>100$ & NAS & & 4 万G & & & \\
\hline 1 & $\begin{array}{c}2,992,900 \\
(>12)\end{array}$ & $\begin{array}{c}65,333 \\
(11)\end{array}$ & $\begin{array}{l}7,833 \\
(10)\end{array}$ & $\begin{array}{c}1,667 \\
(11)\end{array}$ & $\begin{array}{l}33 \\
(8)\end{array}$ & $>12$ & 22/17 & 0.23 & & 360 & フィルタ入口 \\
\hline 2 & $\begin{array}{c}2,665,770 \\
(>12)\end{array}$ & $\begin{array}{c}42,900 \\
(10)\end{array}$ & $\begin{array}{c}11,400 \\
(11)\end{array}$ & $\begin{array}{c}2,667 \\
(11)\end{array}$ & $\begin{array}{l}33 \\
(8)\end{array}$ & $>12$ & $21 / 16$ & 0.18 & & 360 & 出口 \\
\hline 3 & $\begin{array}{c}2,525,620 \\
(>12)\end{array}$ & $\begin{array}{c}132,190 \\
(12)\end{array}$ & $\begin{array}{l}5,213 \\
(10)\end{array}$ & $\begin{array}{l}93 \\
(7)\end{array}$ & $\begin{array}{l}20 \\
(7)\end{array}$ & $>12$ & $22 / 18$ & 0.21 & & 1,200 & 出口 \\
\hline 4 & $\begin{array}{c}882,720 \\
(12)\end{array}$ & $\begin{array}{l}1,550 \\
(6)\end{array}$ & $\begin{array}{l}120 \\
(4)\end{array}$ & $\begin{array}{l}30 \\
(5)\end{array}$ & $\begin{array}{c}1 \\
0 \\
(0)\end{array}$ & 12 & $20 / 11$ & 0.24 & $<0.01$ & 2,200 & 出口 \\
\hline 5 & $\begin{array}{c}1,888,700 \\
(>12)\end{array}$ & $\begin{array}{l}45,007 \\
(10)\end{array}$ & $\begin{array}{l}607 \\
(7) \\
\end{array}$ & $\begin{array}{l}63 \\
(6)\end{array}$ & $\begin{array}{c}0 \\
(0)\end{array}$ & $>12$ & $21 / 16$ & 0.15 & $<0.01$ & 4,000 & 出口 \\
\hline 6 & $\begin{array}{c}476,767 \\
(11)\end{array}$ & $\begin{array}{c}2,750 \\
(6)\end{array}$ & $\begin{array}{l}517 \\
(7)\end{array}$ & $\begin{array}{l}67 \\
(6)\end{array}$ & $\begin{array}{c}0 \\
(0)\end{array}$ & 11 & $19 / 12$ & 0.14 & $<0.01$ & 5,000 & 出口 \\
\hline
\end{tabular}

表 $5 \mathrm{~K}$ 社 エンジン潤滑油粒子数測定值不安定例

\begin{tabular}{|c|c|c|c|c|c|c|c|c|c|c|}
\hline \multirow[b]{2}{*}{ No } & \multicolumn{6}{|c|}{ 粒 子 数 測 定(個数 $/ 100 \mathrm{ml})$} & \multirow{2}{*}{$\begin{array}{c}\text { ISO } \\
4406\end{array}$} & \multirow{2}{*}{$\begin{array}{l}\text { サンプル } \\
\text { 採取場所 }\end{array}$} & \multirow{2}{*}{$\begin{array}{l}\text { 測定 } \\
\text { 会社 }\end{array}$} & \multirow{2}{*}{$\begin{array}{c}\text { 洗浄時間 } \\
\mathrm{hr}\end{array}$} \\
\hline & $5 \sim 15 \mu \mathrm{m}$ & $15 \sim 25$ & $25 \sim 50$ & $50 \sim 100$ & $>100$ & NAS & & & & \\
\hline 6-1 & $\begin{array}{c}212,705 \\
(10)\end{array}$ & $\begin{array}{c}2,705 \\
(6)\end{array}$ & $\begin{array}{c}380 \\
(6)\end{array}$ & $\begin{array}{l}35 \\
(5)\end{array}$ & $\begin{array}{l}10 \\
(6)\end{array}$ & 10 & $18 / 12$ & $\begin{array}{c}\text { 洗浄装置 } \\
\text { 出口 }\end{array}$ & S社 & 1,520 \\
\hline 6-2 & $\begin{array}{c}709,982 \\
(12)\end{array}$ & $\begin{array}{c}98,787 \\
(12)\end{array}$ & $\begin{array}{c}21,940 \\
(12)\end{array}$ & $\begin{array}{c}579 \\
(9) \\
\end{array}$ & $\begin{array}{l}13 \\
(6) \\
\end{array}$ & 12 & 20/17 & $\begin{array}{c}\text { 洗浄装置 } \\
\text { 出口 }\end{array}$ & K社 & 1,520 \\
\hline 6-3 & $\begin{array}{c}888,228 \\
(12)\end{array}$ & $\begin{array}{c}73,929 \\
(11)\end{array}$ & $\begin{array}{c}1,516 \\
(8)\end{array}$ & $\begin{array}{l}117 \\
(7)\end{array}$ & $\begin{array}{l}20 \\
(7)\end{array}$ & 12 & 20/17 & $\begin{array}{c}\text { エンジン } \\
\text { 入ロ }\end{array}$ & K社 & 1,520 \\
\hline $7-1$ & $\begin{array}{c}2,645,770 \\
(>12)\end{array}$ & $\begin{array}{c}117,085 \\
(12)\end{array}$ & $\begin{array}{c}4,325 \\
(10)\end{array}$ & $\begin{array}{l}130 \\
(7)\end{array}$ & $\begin{array}{l}15 \\
(7) \\
\end{array}$ & $>12$ & $22 / 17$ & $\begin{array}{c}\text { 洗浄装置 } \\
\text { 出口 }\end{array}$ & S社 & 1,650 \\
\hline $7-2$ & $\begin{array}{c}188,281 \\
(10)\end{array}$ & $\begin{array}{c}73,057 \\
(11)\end{array}$ & $\begin{array}{c}31,680 \\
(12)\end{array}$ & $\begin{array}{l}195 \\
(8)\end{array}$ & $\begin{array}{c}8 \\
(5)\end{array}$ & 12 & $19 / 17$ & $\begin{array}{c}\text { 洗浄装置 } \\
\text { 出口 }\end{array}$ & K社 & 1,650 \\
\hline
\end{tabular}

による計測ではK $\mathrm{K}$ 社約 $26 \mathrm{mg}$ に対し，M社 $135 \mathrm{mg}$ で あり，不溶分の質量は $\mathrm{M}$ 社が $\mathrm{K}$ 社の約 5 倍である. それにもかかわらず, ISO-4406の表示ではK社 が $22 / 17, \mathrm{M}$ 社が $19 / 12$ となり，M社のLOの方 が非常にきれいということになる。この矛盾は， 粒子測定による評価法において，5 $\mu$ m以下の粒子 が無視されているが, 污染物の総質量は5 $\mu \mathrm{m}$ 以下 が圧倒的に多いからである.

\subsection{2 粒子数計測の不安定性}

表5は粒子測定の安定性を調べるために行った計 測結果である.K社のサンプリングは通常, 清浄 機出口である．6-1と6-2は同じサンプルを $\mathrm{S}$ 社 と $\mathrm{K}$ 社で計測したもの，6-3は6-1と同時刻に， エンジン入口で採取したサンプルをK社が計測し た結果である．3者は，ほとんど同じ結果になるも のと予想したが，結果には大きな違いがある。こ れを確認するため, 約 1 力月後に再び, $\mathrm{S}$ 社と $\mathrm{K}$ 社

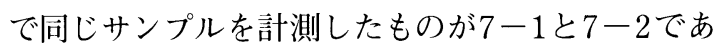
るが, 両者には大差があり, 粒子数の計測には再 現性がなく，極めて不安定であることが分かった。 な打，6-1に比べて $7-2$ の粒子数が多いのは，
7 -2は運転直後だからである.

\subsection{3 粒子数による評価法の非妥当性}

油圧機器においては, サーボ弁のノズル, ノズ ルフラッパ等に大粒子, 特に固形の大粒子が 1 個で もひっかかれば，それは直ちにサーボ弁不調によ る機器の䛊作動, 等の重度障害になる。したがっ て, 油圧機器では個数は少なくても, 大きい粒子 が大敵である.

エンジンでは柔らかい粒子が主体であるが, 大 きい粒子が間欠的に摺動面に現われ，付着しても 直ぐには障害にならない。また污れ粒子であって も潤滑性ゼロではない。これに対して微粒子は集 合して大粒子を形成し，穴に引っかけて污れを除 去する従来型のフィルタでは, フィルタ目詰りを 生じさせる ${ }^{(6)}$.

以上の結果を総括すれば, $\mathrm{d}>5 \mu \mathrm{m}$ の領域の粒 子数でLO污染を評価することは, エンジンLOの 実体を正しく反映していない。油圧機器作動油の 污染評価法を便宜的に適用したものと考えられ， 粒子数によるエンジンLOの評価法が必要かどうか 検討すべきである。 


\section{3. 結 論}

(1)ペンタン不溶分の遠心分離に，A，B法ともに 600〜 700Gでは不十分である.

(2) ISO - 4406の粒子数計測では, $5 \mu \mathrm{m}$ 以下の粒 子は無視されているに等しいが, 污染物の総質 量の約 $99 \%$ は $5 \mu \mathrm{m}$ 以下の粒子である.

(3) 粒子数の計測結果は極めて不安定であり, LO 污染度の評価には不適当と考えられる。

(4)計測結果が不安定であるのは, エンジンLOの 污染物の主体は, $1 \mu \mathrm{m}$ 以下の煤であり, これ が絶えず分散, 集合しているためと考えられる.

(5) 粒子数測定による污染度の計測・評価法が, 必 要かどうか検討を要する.

\section{参考文献}

（1）東·住本·木村, 舶機誌，33-6 (1998-6)，406 411

（2）東·住本·木村, 舶機誌, $35-3$ (2000-3)，178～189

(3) 東 ·住本 · 木村, 日本油空圧学会誌, 34-4 (2000-4)

（4）住本·東·杢村, 水環境学会誌, $23-1(2000-1)$, $55 \sim 58$

（5）燃料潤滑油用語事典，成山堂書店 (1994)，48

（6）横松, 三藤 -小泉, 舶機誌, 33-11 (1998/11), $808 \sim 814$

メッセージ

LOの添加剂については, 機械

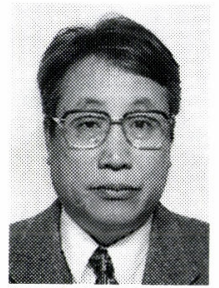

木村 功 技術者の多くは殆ど, 良く理解 しないまま，使用してきた， エンジンLO中の不溶解分は, $1 \mu \mathrm{m}$ 以下の超微粒子の質量が $90 \%$ 以上を占め, 污染粒子は個 数も全質量も, $1 \mu \mathrm{m}$ 以下の粒 子が压倒的に大きい。これまで は, 污れの主体は大きい粒子と 考えていたので, 計測によって この事実を知った時は，正直な ところ警いた．従来の清浄システムでは1 $\mu \mathrm{m}$ 以下は除去不 可能であるが, kidney systemでは除去可能である。これま での経験では分散剤が多いと， $0.1 \mu \mathrm{m}$ 級の粒子が油中に強 力に分散されているため，小さい粒子が集合して大きくな りにくい. そして, kidney systemのフィルタでも, 除去す る際のじゃまになっていると推定される. そこで, kidney systemで $0.1 \mu \mathrm{m}$ 級の粒子を効果的に除去するには, 分散剤 の少ないLOがよい. 従って, 現在の標準オイルにこだわる ことは，大きなマイナスになる場合のあることを理解して ほしい.

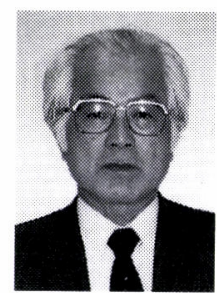

東 忠則

LOに係わるようになってか ら, 我々機械技術者が, いかに LOのことを知らないか痛感して いる. LOのことを知らないため に, エンジンや油圧機器などで, 油をどの程度きれいにしておけ ばよいのか, 污染度をどう計測 し、判断すればよいのか等が, 正しく行われていないように思 われる。本報は、このような問 題へ踏み込んだ筆者等の第一歩 である。

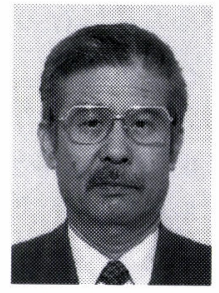

住本守央
廃棄物に対する環境への影響 は,リサイクル法等の法制化に より, 発生企業の責任が益々重 くなる傾们にある。廃油ゼロ対 策技術は，廃油が産業廃棄物と されている以上その確立は急が れている。幸い我々の開発して いる廃油ゼロシステムは, 環境 保全のみならず資源保護や，工 ンジンの信頼性を向上される技 術としてFO管理とLO管理を合わせた予防工学的見地から 見たもので, 廃油排出者のメリットは測り知れないものが あり，投資効果面でも有効である. 